\title{
Short communication: Risk factors associated with Mycobacterium avium ssp. paratuberculosis introduction into dairy herds in Galicia, northwestern Spain
}

\author{
F. J. Villamil, ${ }^{1}$ E. Yus, ${ }^{2}$ B. Benavides, ${ }^{3}$ J. Casal,,${ }^{4,5}$ S. J. Moya, ${ }^{4}$ A. Allepuz, ${ }^{4,5}$ and F. J. Diéguez ${ }^{6 *}$ \\ ${ }^{1}$ Agrupación de Defensa Sanitaria (ADSG), Costa da Morte, 15153, A Coruña, Galicia, Spain \\ ${ }^{2}$ Institute of Food Analysis and Research (Animal Health and Epidemiology Unit), Veterinary Faculty of Lugo, Santiago de Compostela University, \\ 27002, Lugo, Spain \\ ${ }^{3}$ Grupo de investigación de Buiatria, Programa Medicina Veterinaria, Facultad de Ciencias Pecuarias, Universidad de Nariño, 522020, Pasto, \\ Colombia \\ ${ }^{4}$ Department of Health and Anatomy Animal, Universitat Autònoma de Barcelona (UAB), 08193, Barcelona, Spain \\ ${ }^{5}$ Centre de Recerca en Sanitat Animal (CReSA)—Institut de Recerca i Tecnologia Agroalimentàries (IRTA), Barcelona, 08193, Spain \\ ${ }^{6}$ Anatomy and Animal Production, and Clinical Veterinary Sciences Department, Veterinary Faculty of Lugo, Santiago de Compostela University, \\ Campus Universitario, 27002 Lugo, Spain
}

\section{ABSTRACT}

This study assessed potential risk factors associated with introduction of Mycobacterium avium ssp. paratuberculosis (MAP) into dairy cattle herds in the Galicia region, northwestern Spain. The study was carried out with data collected from 93 dairies enrolled in a voluntary MAP control program. Information on potential risk factors was obtained through personal interviews with the farmers and veterinarians in charge of the control program of each farm. In addition, blood samples were taken annually over 2 years from cows on the farms in the program, and analyzed with a commercial ELISA to detect antibodies to MAP. Fecal samples of all ELISA-positive cows were analyzed using PCR. Based on $\chi^{2}$ test and Fisher's exact test, purchase practices, shared manure truck, shared materials, and visitors per month who contacted animals were found to be significantly associated with farm MAP infection status. Multiple logistic regression indicated that purchase practices and herd size (included as a potential confounder) are the variables that best predict MAP status.

Key words: cattle, external biosecurity, Johne's disease, logistic regression

\section{Short Communication}

Mycobacterium avium ssp. paratuberculosis (MAP) is the causal agent of paratuberculosis, also known as Johne's disease. The disease causes serious economic losses in dairy farming, mainly as a result of reduced

Received January 16, 2020.

Accepted April 13, 2020.

*Corresponding author: franciscojavier.dieguez@usc.es milk yield (Richardson and More, 2009), increased susceptibility to other diseases, especially mammary infections (Tiwari et al., 2005), loss of body weight (Mato et al., 2017), and consequential premature culling (Mato et al., 2015). Paratuberculosis has also been related to reduced fertility rates (Smith et al., 2010). Also long suspected to be a cause of Crohn's disease in humans, MAP has recently been proposed as a cause of ulcerative colitis (Pierce, 2018).

The MAP bacterium is usually introduced into herds through the purchase of infected but clinically normal cattle. Other routes, such as the introduction of contaminated feces by vehicles, equipment, visitors, contaminated pasture or water sources, or other ruminants, are less common but may be involved (McAloon et al., 2017; Puerto-Parada et al., 2018; Correa-Valencia et al., 2019). Biosecurity is therefore of paramount importance to prevent the introduction of MAP to herds.

The region of Galicia is the main dairy cattle area of Spain, contributing to $55 \%$ of the nation's farms and $38 \%$ of national milk production. The mean Galician herd size per farm is 43 cows, lower than the national average of 59.3, and the farms are still predominantly family-owned and managed (MAPAMA, 2018). In addition, the dairy farming population is characterized by high farm density and low availability of grass land surface. In this region, important shortcomings in the application of dairy biosecurity measures have recently been described, mainly regarding vehicles and control of visitors (Benavides et al., 2018).

The aim of this study was to identify risk factors associated with MAP introduction into dairy herds in Galicia, northwestern Spain, where a voluntary regional control program against MAP was established in 2004. The study is part of a larger project on risk analysis for the introduction of endemic diseases to cattle herds. 
As part of the farm selection process, the project was first described to the veterinarians responsible for the control program in each farm. The veterinarians who were willing to collaborate then explained the project to farmers during their routine farm visits. Ninetythree dairy farmers were enrolled voluntarily and were not incentivized.

Information on farm biosecurity from the 93 farms was obtained through a questionnaire that was designed based on a literature review (Vilar et al., 2015; Wolf et al., 2016; McAloon et al., 2017) as well as on discussions with researchers and veterinarians at the Santiago de Compostela University and the Autonomous University of Barcelona, regional government veterinarians, and cattle veterinarians of diverse subspecialties. The questionnaire was completed through personal interviews with the farmer and the veterinarian responsible for the control program at each farm between July 2017 and April 2018. It was first administered to 3 test farms, none of which were included in the main sample, to assess the clarity of the questions and whether respondents had suggestions for improvement. As a result of this survey, minor modifications were made to the questions. When the questionnaires were completed, 8,401 dairy farms were operational in Galicia, of which 4,579 $(55 \%)$ were involved in the control program. Thus, the 93 farms represented $2.03 \%$ of the total dairy farms under control.

The questionnaire (available in Spanish upon request) consisted of closed-ended questions and included 4 sections: (1) general farm information (location, herd size); (2) animal movements (e.g., frequency of introductions, sanitary status in origin farm, external rearing farms, cattle fairs or competitions, pasture) and neighborhood (i.e., other ruminant farms in a $1-\mathrm{km}$ radius, small ruminants on the same farm); (3) movements and types of vehicles and equipment (for live and dead animal transport, manure, slurry and feeding vehicles, machinery or materials) and biosecurity-related measures (e.g., vehicles may enter inside the farm perimeter, vehicles may enter with other animals); and (4) visitors and staff (e.g., external workers; frequency of visits by professionals, such as veterinarians and technicians, or nonprofessionals, such as neighboring farmers, who come in contact with the animals, use of protective clothing; Supplemental Table S1, https: //doi.org/10.3168/jds.2020-18210). The questionnaire captures the farming practices within the past 2 years, including number of animal purchases and number of external employees.

Blood samples from all farms included in the program were taken annually from cows over 2 years. The serum was analyzed for anti-MAP antibodies with commercial ELISA (Paratuberculosis Screening Ab Test;
IDEXX, Westbrook, ME), and fecal samples of all ELISA-positive samples were analyzed via PCR (ID Gene Paratuberculosis Duplex; IDvet, Grabels, France). The estimated sensitivity and specificity of the ELISA test are $34 \%$ and $96 \%$, respectively (Aly et al., 2014).

Paratuberculosis is endemic in the cattle population of Galicia. In 2017, for herds under control, the prevalence of serum antibodies at the animal and herd level (a herd was positive when 1 or more individual animals tested positive) was $1.77 \%$ and $17.14 \%$, respectively (I. Arnaiz, Animal Health and Production Laboratory of Galicia, Lugo, Spain; personal communication). Based on the mentioned prevalence of serum antibodies at the animal level, the estimated positive predictive value for the ELISA test was $40.5 \%$.

The 93 herds included in the study were classified as either MAP positive or MAP negative based on the laboratory results obtained in the 2 annual samplings performed before the completion of the questionnaire. Herds with no seropositive cows in both annual samplings were classified as negative $(\mathrm{n}=67)$. Herds with either confirmation of the bacterium by PCR or seropositivity $\geq 15 \%$ without confirmation in any of the annual samplings were classified as positive $(\mathrm{n}=16)$. To minimize misclassification, the remaining herds, which had seropositivity $\leq 15 \%$ without confirmation of the bacterium, or seronegative herds with only 1 annual sampling because they had recently joined the program $(\mathrm{n}=10)$, were not included in the analysis. The time elapsed between the last sampling of the 2 considered and completion of the questionnaire varied among farms, ranging between 1 and 4 mo (Figure 1).

Statistical tests were performed using SPSS version 15.0 (SPSS Inc., Chicago, IL). Candidate risk factors were tested for their association with the MAP infection status of the herds initially by using $\chi^{2}$ test or Fisher's exact test with $\mathrm{k} \times 2$ tables. All factors with moderate statistical significance $(P<0.25)$ in these analyses were incorporated into a multiple logistic model (Wald test forward stepwise, $P$-Wald value of 0.05 to enter). Herd size was also included as a potential confounder (Puerto-Parada et al., 2018); if this variable changed the effect of the remaining coefficients by $10 \%$ or more, it was considered a confounder and stayed in the model, regardless of its level of significance (Doménech, 2004). The variables used in the regression analysis were chosen upon a correlation analysis [using Spearman's rank correlation coefficient $(\rho)$ ] to avoid multicollinearity. Additionally, the goodness of fit of the logistic model was tested using Cox and Snell's $\mathrm{R}^{2}$ and Nagelkerke's $\mathrm{R}^{2}$ (Walker and Smith, 2016).

The potential risk factors whose associations with the infection status had $P$-values $\leq 0.25$ were average frequency of cattle purchased per year and sanitary sta- 
Table 1. Multiple logistic regression model to evaluate risk factors for Mycobacterium avium ssp. paratuberculosis infection according to data obtained from 83 dairy herds in Galicia (northwestern Spain) ${ }^{1}$

\begin{tabular}{|c|c|c|c|c|c|}
\hline \multirow[b]{2}{*}{ Item } & \multirow[b]{2}{*}{$\mathrm{B}$} & \multirow[b]{2}{*}{$P$-value } & \multirow[b]{2}{*}{$\operatorname{Exp}(\beta)$} & \multicolumn{2}{|c|}{$95 \%$ CI of $\exp (\beta)$} \\
\hline & & & & Lower & Upper \\
\hline Herd size ${ }^{2}$ & & 0.060 & & & \\
\hline $47-117$ & 0.069 & 0.923 & 1.071 & 0.263 & 4.361 \\
\hline$>117$ & 2.043 & 0.026 & 7.712 & 1.276 & 46.615 \\
\hline Average frequency of cattle purchased per year/ & & 0.269 & & & \\
\hline 1-3/Negative & -19.335 & 0.999 & 0.000 & 0.000 & - \\
\hline $1-3 /$ Positive or unknown & -19.356 & 0.999 & 0.000 & 0.000 & - \\
\hline$>3 /$ Negative & -19.387 & 0.999 & 0.000 & 0.000 & - \\
\hline$>3 /$ Positive or unknown & 1.716 & 0.023 & 5.561 & 1.270 & 24.360 \\
\hline Constant & -12.436 & 0.999 & 0.000 & & \\
\hline
\end{tabular}

${ }^{1} \mathrm{~B}=$ regression coefficient, $\operatorname{Exp}(\beta)=$ regression coefficient exponential.

${ }^{2} \leq 47$ is the base; 47 is the median herd size in the study population, and 117 is the 90th percentile.

${ }^{3}$ No purchase of cattle is the baseline. Three is the median frequency of entries for farms that buy animals. The sanitary status of the origin herd was considered known if it had a testing protocol comparable or superior to that in herds in the control program in Galicia (negative when all animals tested negative in all tests performed in the last sampling before the purchase of the animals or positive if at least one animal tested positive in any test). The sanitary status of the origin herd was considered unknown in any other case (no testing protocols or testing protocols inferior than that carried out in Galicia).

tus of the origin farm $(P=0.016)$, shared manure truck $(P=0.049)$, shared materials $(P=0.019)$, vehicles transporting live animals to slaughter or feedlot that may come with other animals $(P=0.123)$, external employees $(P=0.247)$, and visits per month that can lead to contact with animals $(P=0.037$; Supplemental Table S1, https://doi.org/10.3168/jds.2020-18210).

Correlation coefficients between the variables considered for multivariable analysis indicated negligible to moderate correlation. The highest values were observed among herd size and visitors per month who contacted animals (0.574), herd size and external employees (0.381), and shared manure truck and vehicles (slaughter or feedlot) that may come with other animals (0.317). The remaining comparatives have values lower than 0.3 .
The regression analysis indicated that herd size and purchase practices were the best predictors (Table 1). Farms that purchased cattle from farms with unknown MAP sanitary status and with an annual average frequency higher than 3 (that is, higher than the median frequency of entries for farms that buy animals) and farms with more than 117 cows (90th percentile of the herd size distribution) were at higher risk. The values of Cox and Snell's $\mathrm{R}^{2}$ and Nagelkerke's $\mathrm{R}^{2}$ of the final model were 0.218 and 0.348 , respectively.

The present paper focuses on factors related to bioexclusion or external biosecurity - that is, factors associated with the entry of MAP into a herd - unlike many other previous studies, in which this topic was assessed together with biocontainment measures. Results of our analysis emphasize the importance of adequate biosecu-

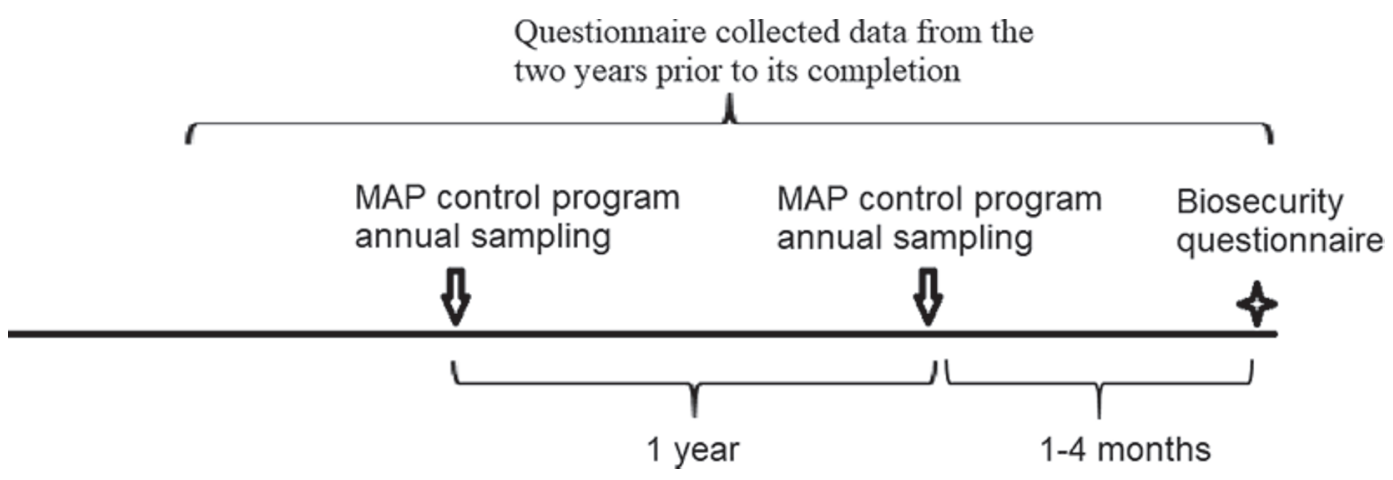

Figure 1. Time frame for the study of risk factors associated with Mycobacterium avium ssp. paratuberculosis (MAP) introduction into dairy cattle herds in the Galicia region, northwestern Spain. 
rity, with the purchase of cattle playing a central role, as other recent studies have done in other populations using other diagnostic approaches (Puerto-Parada et al., 2018; Correa-Valencia et al., 2019).

Only $33.7 \%(\mathrm{n}=28)$ of the studied farms purchased cattle. The primary difference between the present study and previous studies is that in Galicia, farms in the control program are required to test all newly purchased animals by using antibody ELISA. Despite this, farms that purchase cattle are still at higher risk, which highlights the limitations of the serum ELISA test at the individual level (Sergeant et al., 2019) and the need for verified and comprehensive information on the overall status of the origin farm (Sweeney et al., 2012; Puerto-Parada et al., 2018). Unfortunately, most farmers do not request such information. In this study, the sanitary status of the origin herd was considered known if it had a testing protocol comparable or superior to that in herds in the control program in Galicia (negative when all animals tested negative in all tests performed in the last sampling before the purchase of the animals or positive if at least 1 animal tested positive in any test). The sanitary status of the origin herd was considered unknown in any other case (no testing protocols or testing protocols inferior to those carried out in Galicia). Variables for frequency of introductions and status of farm of origin were combined into a single variable for this analysis because exploratory modeling showed significant interaction between the variables, and the combined variable provided a more parsimonious model.

The present study also assessed some factors that have previously received little attention. Some of the factors that were significant in the univariate analysis should not be underestimated, including the control of some shared vehicles (i.e., manure truck), materials, and especially visitors who have contact with the animals. Family-type farms, frequent in Galicia, sometimes require timely collaboration with neighboring farmers, as in the case of a calving, or receive courtesy visits from them, because such farms function with close links between the farm and the house of the farmer, as has been described elsewhere (Moya et al., 2020). According to the observations of the present study, all farms could receive visitors who, without adequate protective clothing, had contact with the animals. Adequate protective clothing was defined as clean coveralls or overcoats and boots that are provided by the farmer before contacting the cattle area.

Herd size was included in the multiple model as a potential confounder. Larger herd size has previously been related to several risk factors, such as increased purchase of animals, increased numbers of visitors (veterinary practitioners, technicians), and the presence of external workers, all of which increase the likelihood of disease introduction and maintenance (Sayers et al., 2015). However, this study, together with a previous study on biosecurity carried out in the same dairy population (Benavides et al., 2018), did not indicate that higher herd sizes imply increased purchase of animals. This could be related to the fact that owners of the smallest farms sometimes combine dairy production with other professional activities that can be diverse (i.e., in other areas of the agricultural sector or in the industry or service sectors; Barbeito and López, 2011). Thus, in small farms, the lack of labor and occasional lack of facilities for rearing heifers may lead to the need for buying animals.

Small farms could also be forced to share vehicles or machinery more often than large farms, which may own these items for exclusive use. However, this association was not observed in the study population. Given the herd sizes in Galicia, even herds considered large for the regional average could have sizes and turnovers that are still insufficient to exclusively use certain vehicles or machinery. Conversely, the data indicated a moderate but positive correlation between herd size and both the number of visitors and the presence of external employees.

With regard to the methodology, a possible limitation is that PCR tests were performed only in seropositive animals. The possibility exists of ELISA-negative but fecal culture-positive cows; some could be the result of passive shedding due to the passage of MAP in the intestinal tract (Pradhan et al., 2009). However, it has been indicated that ELISA-positive dams are up to 8.8 times more likely to shed the bacteria (Ayele et al., 2005), and for the present study, laboratory data were assessed at the herd level, not the individual level.

The questionnaires did not include information regarding the farmer's decision to participate in the MAP voluntary control program. The regional government in Galicia encourages participation by defraying most of the cost of laboratory tests and the salary of the veterinarian responsible for the program, in addition to providing preference in the distribution of some subsidies.

The questionnaires were completed during face-toface interviews on farms, with the veterinarian responsible for the control program present. This enabled us to explain the questions and check the validity of many of the responses in situ for better control of bias related to the social desirability response. However, it is important to keep in mind that farmers enrolled voluntarily in the study, and therefore our results cannot be extrapolated directly to all cattle farms in Spain. Despite the inherent limitations, we believe that this study provides comprehensive information on the main 
factors that can lead to the entry of MAP into Galician cattle farms.

\section{ACKNOWLEDGMENTS}

This research was supported by a project from the Ministry of Science and Innovation of Spain (AGL201677269-C2-2-R). The authors have not stated any conflicts of interest.

\section{REFERENCES}

Aly, S. S., R. J. Anderson, R. H. Whitlock, and J. M. Adaska. 2014. Sensitivity and specificity of two enzyme-linked immunosorbent assays and a quantitative real-time polymerase chain reaction for bovine paratuberculosis testing of a large dairy herd. Int. J. Appl. Res. Vet. Med. 12:1-7.

Ayele, W. Y., P. Svastova, P. Roubal, M. Bartos, and I. Pavlik. 2005. Mycobacterium avium subspecies paratuberculosis cultured from locally and commercially pasteurized cow's milk in the Czech Republic. Appl. Environ. Microbiol. 71:1210-1214. https://doi.org/ 10.1128/AEM.71.3.1210-1214.2005.

Barbeito, F., and C. López. 2011. Resultados técnico-económicos das explotacións de vacún de leite en Galicia. 1st ed. Xunta de Galicia, Galicia, Spain.

Benavides, B., A. Allepuz, E. Yus, J. Casal, J. Moya, and F. J. Diéguez. 2018. Sanitary status against bovine viral diarrhea and infectious bovine rhinotracheitis and biosecurity measures applied in dairy farms in Catalonia and Galicia. Page 576 in Proc. 15th International Symposium on Veterinary Epidemiology and Economics, Chiang Mai, Thailand.

Correa-Valencia, N. M., N. F. Ramírez, J. C. Arango-Sabogal, G. Fecteau, and J. A. Fernández-Silva. 2019. Prevalence of Mycobacterium avium ssp. paratuberculosis infection in dairy herds in Northern Antioquia (Colombia) and associated risk factors using environmental sampling. Prev. Vet. Med. 170:104739. https://doi .org/10.1016/j.prevetmed.2019.104739.

Doménech, J. M. 2004. Análisis multivariante. Modelos de regresión. UD6. Construcción de un modelo de regresión múltiple para evaluar un efecto en presencia de interacción y confusión. 1st ed. Signo, Barcelona, Spain.

MAPAMA (Ministerio de Agricultura y Pesca, Alimentación y Medio Ambiente de España). 2018. Panel situación sector lácteo España. Accessed Dec. 2, 2019. https://www.mapa.gob.es/es/estadistica/ temas/estadisticas-agrarias/resultados_provisionales_may2019 _bovino_webmapa_tcm30-514025.pdf.

Mato, I., N. Pesqueira, C. Factor, F. Camino, M. L. Sanjuán, E. Yus, and F. J. Diéguez. 2017. Effect of Mycobacterium avium ssp. paratuberculosis serostatus on carcass weight and conformation and fat cover scores. Span. J. Agric. Res. 15:e0502. https://doi.org/10 $.5424 / \mathrm{sjar} / 2017151-10266$.

Mato, I., N. Pesqueira, C. Factor, M. L. Sanjuan, E. Yus, R. Fouz, I. Arnaiz, F. Camino, and F. J. Diéguez. 2015. Effect of Mycobacterium avium ssp. paratuberculosis infection status on culling and calving difficulty in dairy cattle. Livest. Sci. 177:151-158. https:// doi.org/10.1016/j.livsci.2015.04.015.

McAloon, C. G., M. L. Doherty, P. Whyte, S. J. More, L. O'Grady, L. Citer, and M. J. Green. 2017. Relative importance of herd-level risk factors for probability of infection with paratuberculosis in Irish dairy herds. J. Dairy Sci. 100:9245-9257. https://doi.org/10 $.3168 /$ jds.2017-12985.
Moya, S., F. Tirado, J. Espluga, G. Ciaravino, R. Armengol, F. J. Diéguez, E. Yus, B. Benavides, J. Casal, and A. Allepuz. 2020. Dairy farmers' decision-making to implement biosecurity measures: A study of psychosocial factors. Transbound. Emerg. Dis. 67:698-710.

Pierce, E. S. 2018. Could Mycobacterium avium subspecies paratuberculosis cause Crohn's disease, ulcerative colitis... and colorectal cancer? Infect. Agent. Cancer 13:1. https://doi.org/10.1186/ s13027-017-0172-3.

Pradhan, A. K., J. S. Van Kessel, J. S. Karns, D. R. Wolfgang, E. Hovingh, K. A. Nelen, J. M. Smith, R. H. Whitlock, T. Fyock, S. Ladely, P. J. Fedorka-Cray, and Y. H. Schukken. 2009. Dynamics of endemic infectious diseases of animal and human importance on three dairy herds in the northeastern United States. J. Dairy Sci. 92:1811-1825. https://doi.org/10.3168/jds.2008-1486.

Puerto-Parada, M., J. C. Arango-Sabogal, J. Paré, E. Doré, G. Côté, V. Wellemans, S. Buczinski, J. P. Roy, O. Labrecque, and G. Fecteau. 2018. Risk factors associated with Mycobacterium avium ssp. paratuberculosis herd status in Québec dairy herds. Prev. Vet. Med. 152:74-80. https://doi.org/10.1016/j.prevetmed.2018.02.010.

Richardson, E., and S. More. 2009. Direct and indirect effects of Johne's disease on farm and animal productivity in an Irish dairy herd. Ir. Vet. J. 62:526-532. https://doi.org/10.1186/2046-0481-62 $-8-526$.

Sayers, R. G., N. Byrne, E. O'Doherty, and S. Arkins. 2015. Prevalence of exposure to bovine viral diarrhoea virus (BVDV) and bovine herpesvirus-1 (BoHV-1) in Irish dairy herds. Res. Vet. Sci. 100:21-30. https://doi.org/10.1016/j.rvsc.2015.02.011.

Sergeant, E. S. G., C. G. McAloon, J. A. Tratalos, L. R. Citer, D. A. Graham, and S. J. More. 2019. Evaluation of national surveillance methods for detection of Irish dairy herds infected with Mycobacterium avium ssp. paratuberculosis. J. Dairy Sci. 102:2525-2538. https://doi.org/10.3168/jds.2018-15696.

Smith, R. L., R. L. Strawderman, Y. H. Schukken, S. J. Wells, A. K. Pradhan, L. A. Espejo, R. H. Whitlock, J. S. Van Kessel, J. M. Smith, D. R. Wolfgang, and Y. T. Gröhn. 2010. Effect of Johne's disease status on reproduction and culling in dairy cattle. J. Dairy Sci. 93:3513-3524. https://doi.org/10.3168/jds.2009-2742.

Sweeney, R. W., M. T. Collins, A. P. Koets, S. M. McGuirk, and A. J. Roussel. 2012. Paratuberculosis (Johne's disease) in cattle and other susceptible species. J. Vet. Intern. Med. 26:1239-1250. https: //doi.org/10.1111/j.1939-1676.2012.01019.x.

Tiwari, A., J. A. Vanleeuwen, I. R. Dohoo, H. Stryhn, G. P. Keefe, and J. P. Haddad. 2005. Effects of seropositivity for bovine leukemia virus, bovine viral diarrhoea virus, Mycobacterium avium subspecies paratuberculosis, and Neospora caninum on culling in dairy cattle in four Canadian provinces. Vet. Microbiol. 109:147-158. https://doi.org/10.1016/j.vetmic.2005.05.011.

Vilar, A. L., C. S. Santos, C. L. Pimenta, T. D. Freitas, A. W. Brasil, I. J. Clementino, C. J. Alves, C. S. Bezerra, F. Riet-Correa, T. S. Oliveira, and S. S. Azevedo. 2015. Herd-level prevalence and associated risk factors for Mycobacterium avium ssp. paratuberculosis in cattle in the State of Paraíba, Northeastern Brazil. Prev. Vet. Med. 121:49-55. https://doi.org/10.1016/j.prevetmed.2015.06.003.

Walker, D. A., and T. J. Smith. 2016. Nine pseudo R2 indices for binary logistic regression models. J. Mod. Appl. Stat. Methods 15:848-854. https://doi.org/10.22237/jmasm/1462077720.

Wolf, R., H. W. Barkema, J. De Buck, and K. Orsel. 2016. Dairy farms testing positive for Mycobacterium avium ssp. paratuberculosis have poorer hygiene practices and are less cautious when purchasing cattle than test-negative herds. J. Dairy Sci. 99:4526-4536. https://doi.org/10.3168/jds.2015-10478. 